\title{
How Informal Social Control Affect the Integrity of Political Participation among Young People?
}

Mohd Sufiean Hassan, Siti Nurshahidah Sah Allam, Abdul Rauf Hj Ridzuan, Rosilawati Sultan Mohideen, llya Yasnorizar llyas, Fazurah Mustaffa

To Link this Article: http://dx.doi.org/10.6007/IJARBSS/v11-i4/9029 DOI:10.6007/IJARBSS/v11-i4/9029

Received: 09 February 2021, Revised: 12 March 2021, Accepted: 31 March 2021

Published Online: 09 April 2021

In-Text Citation: (Hassan et al., 2021)

To Cite this Article: Hassan, M. S., Allam, S. N. S., Ridzuan, A. R. H., Mohideen, R. S., Ilyas, I. Y., \& Mustaffa, F. (2021). How Informal Social Control Affect the Integrity of Political Participation among Young People? International Journal of Academic Research in Business and Social Sciences, 11(4), 20-36.

\section{Copyright: @ 2021 The Author(s)}

Published by Human Resource Management Academic Research Society (www.hrmars.com) This article is published under the Creative Commons Attribution (CC BY 4.0) license. Anyone may reproduce, distribute, translate and create derivative works of this article (for both commercial and non-commercial purposes), subject to full attribution to the original publication and authors. The full terms of this license may be seen at: http://creativecommons.org/licences/by/4.0/legalcode

Vol. 11, No. 4, 2021, Pg. 20 - 36

Full Terms \& Conditions of access and use can be found at http://hrmars.com/index.php/pages/detail/publication-ethics 


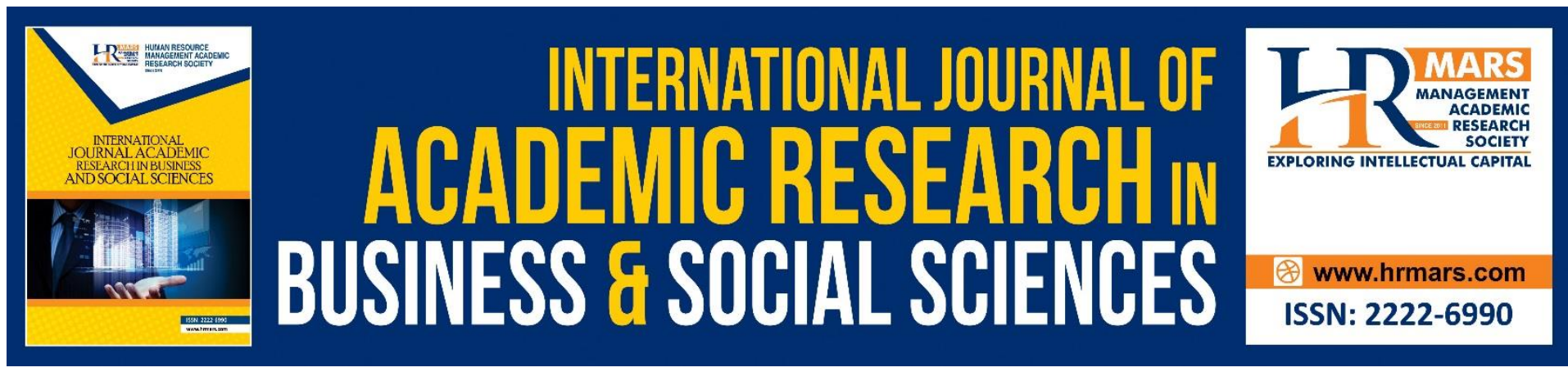

\title{
How Informal Social Control Affect the Integrity of Political Participation among Young People?
}

\author{
Mohd Sufiean Hassan, Siti Nurshahidah Sah Allam, Abdul Rauf \\ Hj Ridzuan, Rosilawati Sultan Mohideen, Ilya Yasnorizar llyas \\ Universiti Teknologi MARA, Melaka Branch, Malaysia
}

Fazurah Mustaffa

Kolej Universiti Islam Melaka, Malaysia

\begin{abstract}
This study aims to measure the influence of social control which consists of the dimensions of attachment, belief and commitment with the integrity of political participation of young people in social media. The study was conducted on 400 students in four for Higher Education Institutions (HEI) in Melaka, namely Universiti Teknikal Malaysia, Melaka (UTeM, Universiti Teknologi MARA, Melaka (UiTM), Universiti Multimedia (MMU), and Kolej Universiti Islam Melaka (KUIM). 400 questionnaires were distributed, only 388 were returned for analysis. Empirical results via the structural equation modeling (SEM) approach revealed a significant relationship between the dimensions of attachment, belief, and commitment to the integrity of political participation. The study found that social control is important to the integrity of political participation, which means that social control through the dimensions of attachment, belief, and commitment gives influence on the behavior of young people with integrity in social media. Furthermore, the integrity of political participation is widely influenced by belief, it showed that most of them believe that God will provide rewards in the form of wealth, status, and power in return. Direction for future research is presented.
\end{abstract}

Keywords: Social Control, Attachment, Belief, Commitment, Integrity Of Political Participation

\section{Introduction}

Crime or non integrity action is an issue and the phenomena that occur in the community. Through certain method, every group of community will tried to control and prevents deviance acts or crime. In order to control and prevent deviance or non integrity behaviour in community, there are two methods of social control that was practices by community which is formal social control and informal social control.

However, for East Asia researchers such like Zhang et al. (1996), Chen (2004), Jiang et al. (2007), they more likely to test the effectiveness of moral and ethical values applied in culture that refers as informal social control for individuals to curb acts of misconduct because of the fact that formal social control is effective only in the short term. 
It is also supported by sociologists and psychologists, Chen (2004) and Jiang et al. (2007), who argue that formal social control through law can not afford to cover all aspects of human life, especially the punishment imposed after misconduct. Formal social control only controls the acts of misconduct rather that prevent and it will take highly implication in term of financial. By doing this we are also force them to obey to the law in order to make sure control non integrity.

In contrast to informal social controls, where it is restricts criminal misconduct through the moral values imposed on individuals, this moral value is accepted by all the world's society, as the effect of applying this moral value is long-term and more importantly it is voluntary to be observed. However, little study focus on informal social control and integrity value among young people. Many researchers from Western country keen to employ formal social control for preventive measure for serious crime rather than uncivil action. The notion is that informal social control only for uncivil behaviour is neither extreme nor harmful enough to attract the attention of the police or to be the subject of formal repression (e.g. compound, penalty, fines or any legal procedures) (Chaurand \& Brauer, 2008). However, this study believe that informal social control method effectively prevent crime action by controlling uncivil action.

Looking at the importance of the integrity of political participation and social control to curb immoral behavior especially in the cultural aspects of Malaysia, this study takes into account the Dimensions of Belief not only in terms of law but also in the aspect of religious beliefs. This study also measures new items for the belief dimension by focusing on religious factors that enhance political participation integrity among young people. Little focus is given by previous study the power of religion in shaping integrity action (Laniyonu, 2018).

- The purpose of this study is to analyze the impact of attachment, belief, and commitment dimensions on the integrity of political participation of young people in social media.

\section{Social Control Theory}

Social Control theory is a theory for preventing non integrity behavior in the society. This theory was developed by sociologist Travis Hirschi around 1967. Social control theory is widely used by researchers to examine delinquent behavior among young people. Hirschi divides the theory of social control into two that is formally and informally.

Formal social control is a control that imposes legal action to curb delinquent behavior and acts of violation of laws such as jail sentence, fine, rattan and so forth. While informal social controls use socialization agencies such as friends, parents, communities and schools or universities. Formal social control has succeeded in reducing misconduct and involuntary of society but this has not been conducive to society. Society will only be effective when supervised.

Theoretical basis and informal social control study is to assess the factors that are expected to curb the individual's behavior from misconduct. This theory is seen to be effective in reducing crime rate, non integrity behavior and devian behavior especially among young people. This is because the youth's lifestyle attachment to socialization agencies such as families and educational institutions is high compared with adults.

The basis of the idea of establishing a social control theory by Reiss (1951) is an individual misconduct constrained through the function of an individual's attachment to himself and the main group and is named as the self control and control of the major groups. Self-control refers to how someone refrains from behavior that is contrary to the norms and 
regulations of society. An individual with high self-control is the result of high social control relationships. Social control refers to how the major groups and social institutions create values, morals and norms effective as a rule to be followed individually.

In addition to families, social institutions such as society and community groups contribute to individual behavior, where individual involvement on a group contributes to the rate of misconduct to be performed. According to Toby (1957), the higher the individual's commitment to the deviant group, the higher the individual's tendency to deviate. However, if individual life is surrounded by a low community group or does not deviate, then the level of self-involvement in devianism is also low. This means that individual self-control is influenced by the behaviors of the participating community groups.

In addition to the self control and behavior of the main group, the theory by Francis Nye (1958) is complemented by the belief of reward and punishment functions, in which the professor in the sociology field divides the elements of individual behavior control into three (3), namely: 1) direct control, 2) indirect controls and 3) internal controls. Direct control refers to the belief that behaviors that are contrary to the values, norms and morals of the society committed by individuals will be punished and good behavior, that compliance is rewarded by main groups such as parents, schools and communities.

In addition to rewards and punishments, values, norms and morals is expected to curb misconduct by individuals and Nye (1958) he was named as an indirect control. For reference the behavior of individuals how to abstain from misconduct, Ivan Nye described as internal control, in which the individual's own refrain from misconduct on the importance of the family in society.

In addition to the belief that human behavior affects the reward and punishment, social control theory also believes that the main commitment of individuals and groups in curbing acts of misconduct by individuals is a major factor. The original idea of this theory containment taken by Reckless (1961) which states that the commitment of individuals and society to curb criminal behavior is a major factor these symptoms should be contained before it happens, with the philosophy of "The Importance of Compliance" or "Stake in Conformity". Therefore, Reckless divided social control to the inner containment and outer containment, in which the inner containment refers to the self (self-concept) as an insulator or barrier to misconduct.

Self-concept refers to an individual's ability and inner strength in keep away from wrongdoing. It depends on the positive encouragement of friends, tolerance to frustration, unable to control his emotions when he failed to live up to expectations and the ability to maintain a grip values, norms and morals. Inner containment addition, social control is discussed by the outer containment Reckless that refers to the social control of environmental factors ranging from family, school, friends and community (club or association).

Among the well-known theorist of social control is Hirschi (1969) that combines the four elements in the Bonding / Social Control Theory discussed earlier, namely 1) attachment, 2) involvement, 3) Belief, 4) Commitments (Intravia 2009). Four elements are expected to be the main factor constraining the misconduct of individuals and these elements combined with the three social groups, namely 1) family, 2) educational institutions (schools) and 3) friends. These social groups build values, morals and ethics in the individual to curb acts of misconduct. However this article is mainly focuses on three element that rarely tested to young people especially related to political participation. This study also contribute new knowledge which is variable belief often being tested on law enforcement, however in Malaysia the culture are difference from western country, they strong on religious belief. The 
combination of the main elements (attachment, belief and commitment) with a social group (family, educational institutions (schools) and friends) support researchers in criminology, sociology and psychology agree that individual behavior is shaped by the major affiliate combination is able to curb in crime action or misconduct.

\section{Attachment}

Hirschi detailed the definition of attachment dimensions in his 1977 study, where attachment refers to a psychological relationship where there is respect, love and obedience between young people and family, university and friends. This idea supported by Schroeder, Giordano dan Cernkovich (2010), who argue that these psychological relationships constitute a high degree of social control, where the young people respect, love and obey their families, universities and friends. The higher the level of social control, and the lower the level of misbehavior of the individual. This is because family, university and friends are a significant unit in the lives of young people who provide moral support in their lives (Barfield-Cottledge, 2011; Chuen et al., 2016).

This finding was also supported by Haydari (2011) which studies informal social control among the Middle East (Turkey) community found significant links between young people's attachment to family, university and friends, where the traditional value of respecting the functioning of family, universities and friends in the Middle East community is expected to be a factor in preventing the act of infidelity of young people. However, this dimension of attachment is also influenced by demographic factors such as income and family education level.

Family that encourage the sharing of ideas and emotions, increase the level of attachment of young people with family (Memon et al., 2018). Family function in helping young people solve problems, make decisions and sharing emotions is expected to reduce young people's tendency to seek solutions outside the home, where this opens up a space of non-integrity act. However, this depends on the level of education and income of a family, which reported low levels of parental education, causing them to work longer hours to cover family income. (Dunifon et al., 2013; Ferris et al., 2013). This leads to less monitoring of academic achievement and providing negative experiences throughout children's development (Han et al., 2010; Han \& Miller, 2009; Lyons-Ruth, 1996).

In addition to family ties, young people's attachment to the university is expected to affect their actions (Wray-Lake et al., 2012), where young people are confident in this social institution in solving problems, making decisions and sharing emotions become an obstacle to the act of infidelity of the young people.

H1: Attachment will have a significant positive effect on the Integrity of Political Participation.

\section{Belief}

Next is the element of belief that refers to the level of compliance values, loyalty and individual beliefs of religious institutions and legislation. The high level of adherence, loyalty and trustworthiness of individuals built by the main affiliates, namely 1) family, 2) educational institutions (school) and 3) friends, the lower the tendency of individuals to engage in unintentional behavior. The idea of Hirschi's idea is the individual's belief in religious institutions as well as the law in restraining acts of misconduct affecting individual behavior against misbehavior. However, if these beliefs are contaminated by the failure of religious 
and legislative institutions, it is likely to give reason to justify the actions of individuals without integrity.

The dimension of belief, refers to the level of values of obedience, loyalty and individual trust in religious and legal institutions (Alston et al., 1995). Previous research highlights from various fields of culture and religion believe that religion is capable of suppressing the act of infidelity of young people. Religious institutions are responsible for instilling the values, morals and ethics of into a community of young people (Obasola, 2013).

Religious practices and voluntary participation in religious activities among young people are expected to increase moral values and integrity. According to Laird et al (2011) in their study of religious function in preventing acts of infidelity, the more often young people participate in religious activities, the higher the value of integrity is cultivated.

The findings of this study are also supported by Ludden (2011) on volunteerism among rural youth, in which he found that young people who participate in religious and volunteerism activities are reported to be less behavioral problems, has high academic motivation and achievement. In addition, these civic activities are not only taking place in residential areas, but also in universities.

The belief that religious institutions are not only able to improve the integrity of the young people, but directly improve academic performance. This idea is supported by Mustapha (2013) who studied religion and acts with integrity among young people found that respondents who have a high religious background has fewer behavior problems (Chamratrithirong et al., 2013).

In addition to religious institutions, the belief in the law and the enforcement of the law in preventing acts of infidelity has also been shown to increase the value of young people's integrity. The belief that every wrongdoing is subject to fair punishment (Jiang et al., 2014) and participation in volunteer activities organized by the enforcement body is expected to curb the act of infidelity of young people (Weisburd \& Eck, 2004).

Although informal social control is expected to be more effective in the long run to discourage unethical behavior, formal social control is still needed because of its short-term effectiveness in controlling acts of non-integrity (Omoyibo \& Obaro, 2012).

H2: Belief will have a significant positive effect on the Integrity of Political Participation.

\section{Commitment}

The last one is the element of commitment that refers to individual commitment in preserving emotions or feelings, views and perceptions of main combination, namely 1) family, 2) educational institutions (school) and 3) friends against the effects of behavior (Baumeister \& Leary, 1995). According to Wheeler et al. (1983) the higher social bonding, the less individual tendency to act non integrity. Although previous studies have proven that social control succeeds in forming individual behaviors but there is very limited studies are conducted in Asian countries such as Malaysia with a multiracial and ethnic group.

Hirschi argues that the higher the level of individual emotional commitment with the key combination, the less individual tendency is to act unintegrated. Support for this argument is a basic human need is security, which is at a safe for no individual in this world who want to live alone and live alone action to trigger depression (Han et al., 2010). The idea of live alone will give negative impact to young people related to the Valdimarsdóttir, \& Bernburg (2015) finding's towards the commitment of young people with social institutions and non integrity acts of young people's. The results of the study report that young people's 
commitments to neighborhood activities can have a negative impact on their level of nonintegrity (Warner \& Burchfield, 2011), where the lower the level of commitment of young people with neighborhood activity, the lower the integrity value of the younger (Thorlindsson et al., 2012).

The low level of integrity of the young people is closely linked to family commitment in applying the values of religion, social and culture within the young people who value the integrity of young people (Chamratrithirong et al., 2013). Fostering the value of integrity of young people by the family, is reported to have a significant relationship between the commitment of the young and the family (Schroeder et al., 2010). This study is consistent with previous literature highlights that young people with high commitment to maintaining good relationships with the family, being individual expectations and paying homage to the family are expected to reduce the tendency of this individual to engage in non integrity activities (Khoury-Kassabri et al., 2015).

In addition, family-born emotional attachment to young people fosters positive emotions, mental health and behavior with integrity compared to young people who lack emotional support from the family. This idea is supported by the study (Chamratrithirong et al., 2013) shows that the high commitment of parents towards young people is a significant predictor of the unfettered action of young people and is largely due to the application of positive emotions.

H3: Commitment will have a significant positive effect on the Integrity of Political Participation.

\section{Research Methodology}

The respondents were 388 university students of four universities in Melaka, Malaysia. The selection of students from Universiti Teknologi MARA, Melaka (UiTM), Universiti Teknikal Malaysia, Melaka (UTeM), Multimedia University (MMU) and Kolej Universiti Islam Melaka (KUIM) based on random sampling. This study uses survey questionnaires where respondent have to fill it by their own a means of collecting data. Based on the number of respondents ( $\mathrm{n}$ $=388$ ) with complete data in this study, the sample size is large enough to use SEM (Hair et al., 2010). Before proceeding to the end of the data collection, a pilot study to test the reliability of the instrument was carried out to ensure the consistency of the questionnaire. Cronbach alpha reliability coefficient for all three variables, more than 0.70 , indicating good internal consistency (Hair et al., 2010). The adapted instrument was reviewed by expert and subsequently pre-test and pilot test was conducted to determine the validity of the question. The purpose of this study was to examine the effects of the dimensions of social control namely attachment, belief and commitment to the integrity of political participation among young people by using structural equation modelling.

\section{Research Instrument}

The questionnaire consists of two parts is used as a research instrument. Part A consists of general information regarding demographic variables such as gender, age, status, ethnicity, education and the use of social media. Part B contains a social control scale adapted from Cho (2014), then translated into Malay. The scale to measure social control is a well-established scale that has proven its reliability because it is widely used in past studies. Reliability (Cronbach alpha) for the three scales of social control - the construct of attachment, belief and commitment is between $0.70-0.83$ (Cho 2014). Use a scale that has been established is 
actually helpful in terms of the reliability scale in getting information through the crowd (Babbie 2013). This scale consists of 29 items and measured using a scale between seven levels, from 1 = strongly disagree to 7 = strongly agree. The measurement scale to measure Attachment, belief and commitment.

\section{Data Analysis}

Data were analyzed using descriptive statistics to describe the profile of the respondents and Confirmatory Factor Analysis (CFA) with the aid of software SPSS AMOS 21.0. CFA aims to determine the number of items included in the construct in line with what is stated in theory (Byrne, 2010). Assessment of model fit CFA is determined by a combination of at least one Absolute Fit Indices and the Incremental Fit Indices (Hu \& Bentler, 1999; Hair et al., 2010) and parsimony Fit Indices (PFI) (Hair et al., 2010). Fit test is used to determine whether the tested model should be accepted or rejected. However, there is no specific rule that determines whether a compatibility index needs to be reported for a model (Hooper, Coughlan \& Mullen, 2008, Hair et al., 2010). The use of three or more index correspondence is sufficient to prove the accuracy of a model to achieve equivalence, without the need to report all existing indices of fit (Hair et al., 2010).

\section{Findings}

The demographic profile of the surveyed respondents is presented in Table 1 . The total sample for the survey consists of 388 respondents. The gender distribution of the survey respondents is $42.5 \%$ females and $57.5 \%$ males. The results also reveal that the respondents are predominantly aged between 21 and 23 years, which is $54.9 \%$ of the sample. More than $85 \%$ of the respondents are married. The majority of the respondents have been educated to college or higher education level: $2.6 \%$ are STPM, 3.6\% are Matriculation, $2.6 \%$ are prediploma, and $59.8 \%$ diploma holders while $32 \%$ have Bachelor degrees. In addition, $49.2 \%$ of the respondents used social media more than ten times a day and $29.6 \%$ have used to update social media accounts 1-30 minutes time. 
Table 1 : Demographic profile of respondents

\section{Profile}

\section{Gender}

Male

Female

Age

$18-20$

21-23

24-26

27-29

30-40

\section{Marital Status}

Single

Married

Other

\section{Religion}

Islam

Christian

Buddha

Hindu

Other

\section{Race}

Malay

Chinese

Indian

Other

\section{Level of Education}

STPM

Matriculation

Pre-Diploma

Diploma

Degree

HEI

UITM 136

UTeM

MMU

KUIM
Frequency

165

223

37

213

88

37

13

338

38

12

290

39

36

17

6

87.1

9.8

3.1

74.7

10.1

9.3

4.4

1.5

286

73.7

66

17.0

19

4.9

17

4.4

10

2.6

14

3.6

10

232

2.6

59.8

124

32.0

99

35.1

100

25.5

25.8

53

Frequency of using social media in a day? 


\begin{tabular}{lll}
\hline 3-5 times & 80 & 20.6 \\
6-10 times & 93 & 24.0 \\
$>10$ times & 191 & 49.2 \\
& & \\
The time used to update social media & & \\
accounts? & & 29.6 \\
$1-30$ minute & 115 & 25.3 \\
31 minute -1 hour & 98 & 21.9 \\
1 hour- 2 hours & 85 & 23.2 \\
$>3$ hours & 90 & \\
\hline
\end{tabular}

\section{Reliability Analysis}

Based on the Confirmatory Factor Analysis (CFA) results, we analyzed convergent validity, discriminant validity, and reliability of all the multiple-item scales, following the guidelines from previous literature (Fornell \& Larcker, 1981). The measurement properties are reported in Tables 2 and 3. Reliability was assessed in terms of composite reliability (CR), which measures the degree to which items are free from random error and therefore yield consistent results. Composite reliabilities in the measurement model ranged from 0.866 to 0.925 (see Table 2), above the recommended cut-off of 0.70 (Fornell \& Larcker, 1981; Nunnally \& Bernstein, 1994).

Table 2 : Reliability and Factor Loadings

\begin{tabular}{llll}
\hline $\begin{array}{l}\text { Construct / Measurement } \\
\text { items }\end{array}$ & Standardized Loadings & CR & AVE \\
\hline Attachment & .507 & 0.779 & 0.502 \\
AT1 & .530 & & \\
AT2 & .569 & & \\
AT3 & .741 & & \\
AT4 & .645 & & \\
AT5 & .648 & 0.832 & 0.558 \\
AT6 & & & \\
Belief & .728 & & \\
BL1 & .842 & & \\
BL2 & .796 & 0.796 & 0.510 \\
BL3 & .598 & & \\
BL4 & & & \\
Commitment & .671 & & \\
CO1 & .650 & & \\
CO2 & .771 & & \\
CO3 & .717 & & \\
CO4 & & & \\
\hline
\end{tabular}

Convergent validity was assessed in terms of factor loadings and average variance extracted (AVE). According to the prior study, convergent validity requires a factor loading greater than 0.50 and an AVE no less than 0.50 . As shown in Table 2, all items had significant factor loadings higher than 0.50. To evaluate discriminant validity, the AVE is used. All constructs have an AVE of at least 0.5. However, according to Fornell \& Larcker (1981), AVE value that below 0.5, 
it is still acceptable if the CR more than 0.7 and all the square roots of each AVE value are higher than the off-diagonal correlation elements (Fornell \& Larcker, 1981).

Table 3 : Correlation matrix and roots of the AVEs (shown as diagonal elements)

\begin{tabular}{lllll}
\hline & 1 & 2 & 3 & 4 \\
\hline (1) Attachment & 0.612 & & & \\
(2) Belief & 0.533 & 0.747 & & \\
(3) Commitment & 0.463 & 0.398 & 0.704 & \\
(4) Integrity of Political Participation & 0.315 & 0.366 & 0.049 & 0.862 \\
Mean & 4.803 & 4.658 & 5.462 & 4.322 \\
Std. Deviation & 1.032 & 1.226 & 1.094 & 1.065 \\
\hline
\end{tabular}

** Correlation is significant at the 0.01 level (2-tailed).

Confirmatory Factor Analysis (CFA) Social Control

Table 4: Confirmatory Factor Analysis (CFA)

\begin{tabular}{lllllllll}
\hline Description & $\chi^{2}$ & CMINDF & RMSEA & GFI & IFI & TLI & CFI & PGFI \\
\hline CFA Model & 324.264 & 2.636 & 0.065 & 0.919 & 0.935 & 0.919 & 0.935 & 0.661 \\
\hline
\end{tabular}

Measurement model in Table 3 showed the goodness of fit with eight indications namely $(\chi 2$, CMINDF, RMSEA, GFI, IFI, TLI, CFI and PGFI) as shown in Table 3. However, Marsh \& Hau (1996) suggest that the value of Chi-square $(\chi 2)$ can be divided by degree of freedom $(\mathrm{df}=100)$ to evaluate the model fit compared to using $\chi 2$ (CMINDF). If the CMINDF statistics count is less than the value of 5, the data fit for the confirmatory factor analysis is good (Marsh \& Hau, 1996). CMINDF for this measurement model is less than value 5 (CMINDF $=2.223$ ). It shows the CFA model quite well. Furthermore, the RMSEA value is 0.056 which is lower than .08 as proposed by Kline (2010). Coefficient of index in Table 3 are all greater than 0.90 indicate a good model fit (Byrne, 2010), and the value of PGFI is greater than 0.5 (.688) which also shows a good model fit with data (Hair, et al., 2010). Fourteen (14) items have been combined due to the high modification index (M.I). Figure 1 shows the CFA Model for this study. 


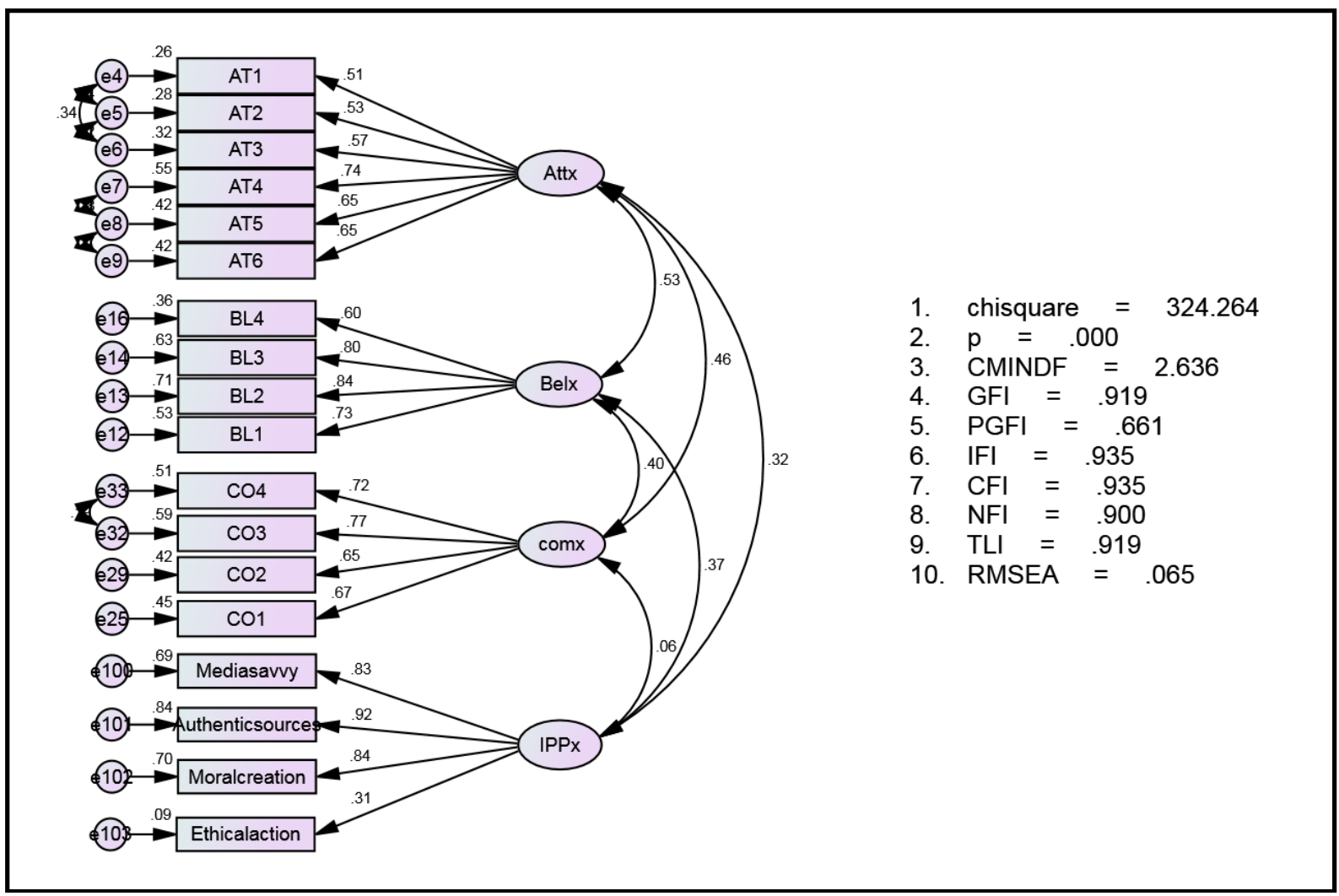

Figure 1 : Confirmatory Factor Analysis (CFA)

\section{Analysis of Paths}

The test of structural model was performed using SEM. The test of the structural model includes: (a) estimating the path coefficients, which indicate the strengths of the relationships between the dependent variables and independent variables, and (b) the R-square value, which represents the amount of variance explained by the independent variables. The path coefficients in the SEM model represent standardized regression coefficients. The structural model reflecting the assumed linear, causal relationships among the constructs was tested with the data collected from the validated measures. Figure 2 shows the results of analysis. The square multiple correlation for the structural equations index indicates that $18 \%$ of the variation in the dependent variable is explained by the variation in the independent variables. Properties of the causal paths (standardized path coefficients ( $\beta$ ), standard error, $p$-value and hypotheses result) are shown in Table 4. 


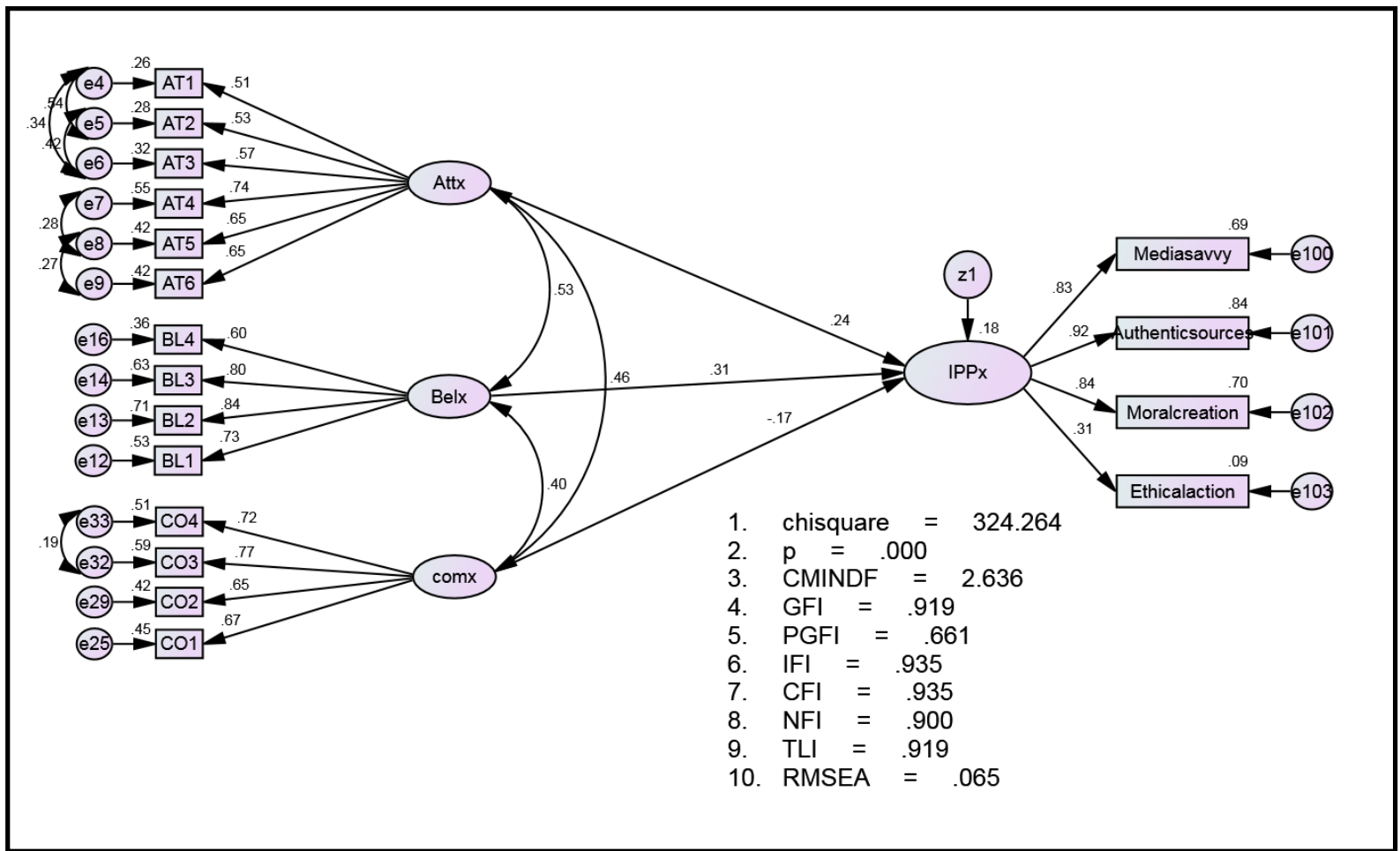

Figure 2 : Estimated research model

\section{Integrity of political participation among young people in social media}

The effect of Attachment on the Integrity of political participation among young people in social media was significant at 0.05 level $(\beta=0.231)$, as presented in Table 4 and Figure 2 . Thus, H1 was supported. Attachment with family, university, and friends would improve young people's integrity in political participation in social media. With a strong attachment with the agent of socialization can counteract the unethical behavior of the young people and influences their political integrity in the virtual world. Beliefs had a significant influence on the integrity of political participation among young people in social media $(\beta=0.302)$. Thus, $\mathrm{H} 2$ was supported. As expected, Commitment had a negative significant influence on the Integrity of Political Participation at 0.01 level $(\beta=-0.178)$, supporting $\mathrm{H} 3$. The expectation commitment of young people to family, friends, and university does affect them in social media.

Table 4: Result of hyphoteses test

\begin{tabular}{llllllll}
\hline \multicolumn{2}{c}{ Dependent Variable } & & $\begin{array}{l}\text { Independent } \\
\text { Variable }\end{array}$ & $\beta$ & S.E. & P & Result \\
\hline $\mathrm{H} 1$ Integrity of & political <--- & Attachment & .231 & .758 & .006 & Supported \\
participation & political <--- & Belief & .302 & .591 & $* * *$ & Supported \\
$\mathrm{H} 2 \begin{array}{l}\text { Integrity of } \\
\text { participation }\end{array}$ & $\begin{array}{l}\text { Integrity of } \\
\text { participation }\end{array}$ & political <--- & Commitment & -.178 & .560 & .006 & Supported \\
H3 & & & & & & & \\
\hline
\end{tabular}

Notes: Path = Relationship between independent variable on dependent variable; $\beta=$ Standardized regression coefficient; S.E. $=$ Standard error; $p=$ Level of significance 


\section{Discussion}

Overall, the findings indicate that informal social control from attachment, belief and commitment dimension significantly affect political participation integrity among young people. This study align with Galais \& Coulombe (2018) findings who study on family and peer attachment pressure young people to vote. Young people's attachment to their families is increased when their families encourage the sharing of thoughts (Memon, Ishak \& Hamid, 2018). The role of the family in assisting young people in solving problems, making decisions, and sharing feelings is expected to decrease young people's desire to seek solutions outside the home, opening up a space for non-integrity act. Apart from that attachment to family with high interest in politics reported increase political interest among young people (Weiss, 2020). By sharing party affiliations, voluntary organisation participation, or young people's real political interest and their parents possible impact on it.

Apart from attachment, this study reported that belief dimension significantly affect political participation integrity among young people. New items measure in this study that little focuses given by previous study was belief in religious can prevent uncivil action. Surprisingly, our new items are significantly contribute towards political participation integrity. Even though religious factor seems least important for political communication scholar to focus and frequently reported has no or negative influence towards political participation (Sönmez, 2019). In addition, many many western researchers reported that current religious factor claims may be exaggerated. They discovered that religion's cognitive dimension has a number of negative consequences for democratic citizenship, especially extreme action such as provocation and joining street demonstration aggressively. However, all this findings are contradictory with current study.

The dimension of belief, refers to the level of values of obedience, loyalty and individual trust in religious and legal institutions (Alston et al., 1995). Many Asian researchers' highlights from various fields of culture and religion believe that religion is capable of suppressing the act of immoral action of young people. Religious institutions are responsible for imparting the values, morals and ethics of into a community (Obasola, 2013) to enhance integrity society.

In addition, religious practices encourage voluntary participation in religious activities among young people are expected to increase civic engagement. Young people interest to engage in civic engagement significantly lead to political participation with integrity value. Laird, Marks and Marrero (2011) reported that religious function in preventing acts of low moral action. The more often young people participate in religious activities and the higher the value of integrity is cultivated.

The findings of this study are also supported by Ludden (2011) on volunteerism among rural youth, in which he found that young people who participate in religious and volunteerism activities are reported to be less behavioral problems, has high academic motivation and achievement. In addition, these civic activities are not only taking place in residential areas, but also in universities.

The dimension of commitment refers to individual commitment in preserving emotions or feelings, views and perceptions of main combination, namely 1) family, 2) educational institutions (school) and 3) friends against the effects of behavior (Baumeister \& Leary, 1995). The findings of this study supported by Wheeler et. al. (1983), which they found that the higher social bonding, the less individual tendency to act non integrity.

Schroeder et al. (2010) also emphasize that commitment of the young people and the family have a significant relationship. This can also fostering the value of integrity among 
young people. This study is consistent with previous literature highlights that young people with high commitment to maintaining good relationships with the family, being individual expectations and paying homage to the family are expected to reduce the tendency of this individual to engage in non integrity activities (Khoury-Kassabri et al., 2015).

\section{Conclusion}

Empirical findings offer academic contributions to the existing body of knowledge of social control as the sophisticated quantitative data analyses used will eventually allow future researchers to explicate the contribution of the current study to understand the importance of factor that influence the integrity of political participation among young people in social media in Malaysia. Input regarding the effects of attachment, belief, and commitment in the integrity of political participation among young peoples would help government and politicians to formulate strategies to enhance their voters in order to obtain moral society and loyal voters, particularly among young peoples. Empirical results via multiple regressions authenticated that belief dimension predominantly affects the integrity of political participation among young peoples. They belief that God will provide rewards in the form of wealth, status and power in return. These young peoples get input and awareness of the integrity of political participation from social support like family and friends from social media. However, future studies should be based on more than the three variables used here. This is because these three variables cannot fully explain the factors influencing the integrity of young people's political participation in social media. Consequently, this findings might be inconclusive. Future researchers should also increase the sample size and ensure that their respondents constitute a balanced demographic and probably add another variables.

\section{Acknowledgement}

This work was supported by Fundamental Research Grant Scheme (FRGS), Malaysia (FRGS/1/2020/SSO/KUIM/03/1).

\section{References}

Babbie, E. (2013). The Practice of Social Research. Canada: Wadsworth, Cengage Learning.

Baumeister, R. F., \& Leary, M. R. (1995). The need to belong: desire for interpersonal attachments as a fundamental human motivation. Psychological Bulletin, 117(3), 497529. https://doi.org/10.1037/0033-2909.117.3.497

Chamratrithirong, A., Miller, B. A., Byrnes, H. F., Rhucharoenpornpanich, O., Cupp, P. K., Rosati, M. J., Fongkaew, W., Atwood, K. A., \& Todd, M. (2013). Intergenerational transmission of religious beliefs and practices and the reduction of adolescent delinquency in urban Thailand. Journal of Adolescence, 36(1), 79-89. https://doi.org/10.1016/j.adolescence.2012.09.011

Chaurand, N., \& Brauer, M. (2008). What determines social control? People's reactions to counternormative behaviors in. Journal of Applied Social Psychology, 38(7), 16891715.

Chen, X. (2004). Social and legal control in China: A comparative perspective. International Journal of Offender Therapy and Comparative Criminology, 48(5), 523-536.

Cho, B. J. (2014). Social Bonds, Self-Control and Deviance of Korean Adolescents. International Journal of Humanities and Social Science, 4(9), 1-8. Retrieved from http://www.ijhssnet.com/journals/Vol_4_No_9_1_July_2014/1.pdf 
Fornell, C., \& Larcker, D. F. (1981). Evaluating structural equation models with unobservable variables and measurement error. Journal of Marketing Research, 18(1), 39. https://doi.org/10.2307/3151312

Galais, C., \& Coulombe, M. (2018). The effect of social pressure from family and friends on turnout. Journal of Social and Personal Relationships, 36(9), 1-18. https://doi.org/10.1177/0265407518802463

Hair, J. F., Black, W. C., Babin, B. J. \& Anderson, R. E. (2010). Multivariate Data Analysis: A Global Perspective. Pearson: Upper Saddle River, NJ.

Han, W. J., \& Miller, D. P. (2009). Parental work schedules and adolescent depression. Health Sociology Review, 18(1), 36-49. https://doi.org/10.5172/hesr.18.1.36

Han, W. J., Miller, D. P., \& Waldfogel, J. (2010). Parental work schedules and adolescent risky behaviors. Developmental Psychology, 46(5), 1245-1267. https://doi.org/10.1037/a0020178

Hirschi, T. (1969). Key idea : Hirschi' S social bond / social control theory. Criminology and Criminal Justice, (1969), 55-69. Retrieved from www.sagepub.com/upmdata/36812_5.pdf

Intravia, J. (2009). The roles of social bonds, personality, and perceived costs: an empirical investigation into hirschi's "new" control theory. University of South Florida.

Jiang, S., Lambert, E. \& Wang, J. (2007). Correlates of formal and informal social/crime control in China: An exploratory study. Journal of Criminal Justice, 35(March 2005), 261-271.

Khoury-Kassabri, M., Khoury, N., \& Ali, R. (2015). Arab youth involvement in delinquency and political violence and parental control: The mediating role of religiosity. American Journal of Orthopsychiatry, 85(6), 576-585. https://doi.org/10.1037/ort0000079

Laniyonu, A. (2018). Police, politics and participation: The effect of police exposure on political participation in the United Kingdom. British Joutnal Crinimol, 1(March), 1-22. https://doi.org/10.1093/bjc/azy003

Lyons-Ruth, K. (1996). Attachment relationships among children with aggressive behavior problems: The role of disorganized early attachment patterns. Journal of Consulting and Clinical Psychology, 64(1), 64-73. https://doi.org/10.1037/0022-006X.64.1.64

Nunnally, J. C., \& Bernstein, I. H. (1994). Psychometric theory (3rd ed.). McGraw-Hill.

Nye, F. I. (1958). Family relationships and delinquent behavior. New York: Wiley.

Reckless, W. C. (1961). A new theory of deliquency and crime. Federal Probation, 25, 42-46.

Reiss, A. J. (1951). Delinquency as the failure of personal and social controls. American Sociological Review, 16(2), 196-207.

Schroeder, R. D., Giordano, P. C., \& Cernkovich, S. A. (2010). Adult child-parent bonds and life course criminality. Journal of Criminal Justice, 38(4), 562-571. https://doi.org/10.1016/j.jcrimjus.2010.04.027

Sönmez, Ö. A. (2019). Religiosity and political participation of university students in religiosity and political participation of university students in Turkey. Mediterranean Journal of Social Sciences, 4(10), 403-409. https://doi.org/10.5901/mjss.2013.v4n10p403

Thorlindsson, T., Valdimarsdottir, M., \& Hrafn Jonsson, S. (2012). Community social structure, social capital and adolescent smoking: A multi-level analysis. Health and Place, 18(4), 796-804. https://doi.org/10.1016/j.healthplace.2012.03.013

Toby, J. (1957). Social disorganization and stake in conformity: complementary factors in the predatory behavior of hoodlums. Journal of Criminal Law, Criminology \& Police Science, 48(1), 12-17. 
Valdimarsdóttir, M., \& Bernburg, J. G. (2015). Community disadvantage, parental network, and commitment to social norms: Multilevel study of self-reported delinquency in Iceland. Journal of Research in Crime and Delinquency, 52(2), 213-244. https://doi.org/10.1177/0022427814548685

Warner, B. D., \& Burchfield, K. (2011). Misperceived neighborhood values and informal social control. Justice Quarterly, 28(4), 606-630. https://doi.org/10.1080/07418825.2010.525518

Weiss, J. (2020). What is youth political participation? Literature review on youth political participation and political attitudes. Frontier in Political Science, 2(1), 1-13. https://doi.org/10.3389/fpos.2020.00001

Wheeler, L., Reis, H. T., \& Nezlek, J. B. (1983). Loneliness, social interaction, and sex roles. Journal of Personality and Social Psychology, 45, 943-953. https://doi.org/10.1037/0022-3514.45.4.943

Zhang, L., Zhou, D., Messner, S. F., Liska, A. E., Krohn, M. D., Liu, J. \& Lu, Z. (1996). Crime prevention in a communitarian society: Bangjiao and Tiao-Jie in the People's Republic of China. Justice Quarterly, 13(2), 199-222. 